\begin{tabular}{|c|c|c|c|c|}
\hline FECHA & PROVEEDOR & QUINA CANTIDAD & PRECIO UNIDAD & PRECIO TOTAL \\
\hline 18-03-1709 & Joseph de Marcos & 68 libras (lb) & $15 \mathrm{Rv} . / \mathrm{lb}$ & - \\
\hline $18-04-1710$ & Joaquín Barrios Merino & 3 arrobas (@) & - & $1.350 \mathrm{Rv}$ \\
\hline $29-07-1712$ & $\begin{array}{l}\text { Gregorio López, } \\
\text { de la Algaba (Sevilla) }\end{array}$ & $100 \mathrm{lb}$ & $1 \mathrm{peso} / \mathrm{lb}$ & - \\
\hline $16-10-1713$ & Joseph de Marcos & $75 \mathrm{lb}$ & 22 Rv. 17 Mrv./lb & 1.687 Rv. 17 Mrv. \\
\hline $11-07-1714$ & Francisco Alfaro & $0.5 @$ & $40 \mathrm{Rv} . / \mathrm{lb}$ & $500 \mathrm{Rv}$. \\
\hline $10-02-1716$ & Joaquín Barrios Merino & $125 \mathrm{lb}$ & $24 \mathrm{Rv} . / \mathrm{lb}$ & $3.000 \mathrm{Rv}$ \\
\hline $26-04-1717$ & Juan Davila & $25 \mathrm{lb} 3$ onzas & $50 \mathrm{Rv} . / \mathrm{lb}$ & $1.260 \mathrm{Rv}$ \\
\hline $21-09-1717$ & Juan Davila & $25 \mathrm{lb}$ & $50 \mathrm{Rv} . / \mathrm{lb}$ & $1.250 \mathrm{Rv}$ \\
\hline 24-11-1717 & Juan Davila & 13 lb y cuarterón & - & $621 \mathrm{Rv}$. \\
\hline 28-05-1718 & Joaquín Barrios Merino & $5 @$ & $28 \mathrm{Rv} . / \mathrm{lb}$ & $3.500 \mathrm{Rv}$ \\
\hline $10-07-1720$ & Joaquín Barrios Merino & 7 @ & 17 Rv./lb & $2.975 \mathrm{Rv}$ \\
\hline $18-06-1721$ & Joseph de Marcos & 4 «cajas» & 16Rv./@ & $1.600 \mathrm{Rv}$. \\
\hline 05-09-1722 & Joseph de Marcos & $50 \mathrm{lb}$ & $16 \mathrm{Rv} . / \mathrm{lb}$ & - \\
\hline $29-10-1723$ & $\begin{array}{l}\text { Bernardo Alfonso } \\
\text { de Guerra }\end{array}$ & $\begin{array}{l}239 \text { lb netas, } \\
\text { de Cádiz }\end{array}$ & - & $3.585 \mathrm{Rv}$ \\
\hline 03-12-1729 & $\begin{array}{l}\text { Joseph Martín Biñas } \\
\text { y Phelipe Hernández }\end{array}$ & $31 @$ & - & - \\
\hline $23-02-1730$ & $\begin{array}{l}\text { Alonso Mendieta, } \\
\text { del Puerto de } \\
\text { Santa María }\end{array}$ & $179 \mathrm{lb}$ & 5 Reales de plata/lb & - \\
\hline $19-11-1735$ & Patricio Joyes y cía & $\begin{array}{l}275 \text { lb y media, de } \\
\text { "cascarilla», en dos } \\
\text { cajones desde Cádiz }\end{array}$ & - & $\begin{array}{l}9.455 \mathrm{Rv} . \\
\text { y } 22 \mathrm{Mrv}\end{array}$ \\
\hline $31-01-1738$ & Manuel Roa & $50 \mathrm{lb}$ & - & $1.000 \mathrm{Rv}$ \\
\hline $25-12-1739$ & Theresa Hubreth & $\begin{array}{l}500 \mathrm{lb} \text {, embarrilada } \\
\text { en Cádiz }\end{array}$ & $19 \mathrm{Rv} . / \mathrm{lb}$ & $9.500 \mathrm{Rv}$. \\
\hline $27-12-1739$ & $\begin{array}{l}\text { Juan de Barrios, } \\
\text { de Bornos (obispado } \\
\text { de Sevilla) }\end{array}$ & $\begin{array}{l}23 \text { @ y cuartilla, } \\
\text { en } 4 \text { barriles, } \\
\text { desde Cádiz }\end{array}$ & 29 Rv./@ & - \\
\hline $04-10-1741$ & Francisco Sierra & $10 @ 13 \mathrm{lb}$ & $22 \mathrm{Rv} . / \mathrm{lb}$ & $5.786 \mathrm{Rv}$ \\
\hline $09-12-1741$ & Gregorio Prieto & $48 \mathrm{lb}$ & 22 Rv. 17 Mrv/lb & $1.080 \mathrm{Rv}$ \\
\hline $16-08-1742$ & Theresa Hubreth & $\begin{array}{l}332 \mathrm{lb} 8 \text { onzas,de } \\
\text { "quina electa» }\end{array}$ & $20 \mathrm{Rv} . / \mathrm{lb}$ & $6.650 \mathrm{Rv}$ \\
\hline
\end{tabular}

\title{
20. EL JARDÍN DE MIGAS CALIENTES DE MADRID DURANTE LA PRIMERA MITAD DEL SIGLO XVIII.
}

\section{Pilar GARCÍA DE YÉBENES TORRES y María Luisa DE ANDRÉS TURRIÓN}

Luis Riqueur (ca. 1655-1737), Boticario Mayor de Felipe V durante el periodo comprendido entre 1701 y 1737 , adquirió una finca, en el camino de la villa de Madrid al real sitio de El Pardo, con ánimo de dedicarla al cultivo, entre otras, de plantas útiles a la farmacia y de productos hortícolas; diez años después de su adquisición fue regalada a Luis 
I (1707-1724) ${ }^{1}$. Con la muerte del joven rey, y el regreso de Felipe $\mathrm{V}$ al trono, la donación se mantuvo, disponiéndose desde la Administración Real que el jardín gozara de una consignación anual y de personal, unos fijos y otros temporeros, en función de las épocas del año y las necesidades del Jardín ${ }^{2}$.

El máximo responsable del cuidado del Jardín fue, desde 1724, Luis Renard; tras su fallecimiento se ocuparon sucesivamente de él sus dos hijos: Luis Renard (entre 1733 y 1739) y Antonio Renard (entre 1740 y 1748), éste con no pocos problemas en la organización del Establecimiento ${ }^{3}$. El personal que trabajaba en el Jardín fue equiparado al de la Real Casa durante la administración de Fernando VI, hacia el $1748^{4}$.

En el momento de su donación, el terreno estaba bien cuidado y con variedad de especies «...tanto de España como de los huertos reales de Paris, Montpellier, Londres y La Haya..." ${ }^{5}$; entre 1730 y 1746 se observa un progresivo deterioro del Jardín ${ }^{6}$, que lleva a los responsables de la Real Botica a solicitar un cambio en la dependencia administrativa del Establecimiento, hasta entonces subordinado al gobierno de la Junta de Obras y Bosques. En 1744, Bartolomé Pérez Durán (m. 1748), Boticario Mayor, intenta reconvertir la trayectoria del Jardín, dedicándolo sólo al cultivo de especies medicinales, bajo la responsabilidad científica de los boticarios reales y al amparo económico de la Real Casa ${ }^{7}$; su sugerencia no tuvo respuesta inmediata, pero una Real Orden de 20-III-1747 conmina a la Junta de Obras y Bosques a trasladar las hierbas medicinales del Jardín al Huerto de La Priora, en la inmediaciones del Palacio Real de Madrid, para protegerlas del riesgo que podrían sufrir durante las operaciones de replanteo en Migas Calientes ${ }^{8}$; la Junta fue la encargada, bajo la dirección del Boticario Mayor, de reunir y colocar las plantas en el lugar que éste eligió; de esta forma quedó desvinculado el Jardín de Migas Calientes de la Real Botica, aunque por breve tiempo; a fines de 1754, y como consecuencia del estado ruinoso en que se encontraba el Jardín de La Priora, a tenor de las obras del nuevo Palacio Real, José Martínez Toledano (m. 1783), el entonces Boticario Mayor, procedió a devolver los plantones a Migas Calientes ${ }^{9}$. El lugar sería considerado pocos meses después como Real Jardín Botánico, por decisión de Fernando VI.

\section{NOTAS}

1. C. Añón Feliú. Real Jardín Botánico de Madrid. Sus orígenes: 1755-1781. Madrid, 1987.

2. Archivo General del Palacio Real de Madrid (A.G.P.), Felipe V, Patrimonio de la Florida, Migas Calientes, leg. 285 (numeración general leg. 3234).

3. Los nombramientos en Archivo General de Simancas (A.G.S.), Secretaría y Superintendencia de Hacienda, leg. 15 (Avisos de Gracia y Justicia, 1723-1739) y en A.G.P., Felipe V, Real Casa, Obras, leg. 460.

4. Orden del Sumiller de Corps al Presidente del Consejo de Estado, 1-X-1748 (A.G.P., Luis I, leg. 3418).

5. Así lo aseguraba Bartolomé Pérez Durán, Boticario Mayor entre 1738 y 1748, en un informe firmado en El Pardo, el 14-I-1744 (A.G.P., Felipe V, Real Cámara, leg. 337). Más detalles en A.G.P., Patrimonio, Florida, leg. 285.

6. En A.G.P. se conservan informes detallados sobre las obras precisas para reparar desperfectos en el Jardín (cf. A.G.P., Felipe V, Patrimonio de la Florida, leg. 285 [numeración general leg. 3234]).

7. Informe de Bartolomé Pérez Durán, 13-I-1744 (A.G.P., Felipe V, Real Cámara, leg. 337).

8. Informe dirigido el Marqués de Solana (A.G..P., Felipe V, Patrimonio de la Florida, Migas Calientes, leg. 285 [numeración general leg. 3234]).

9. Informe del Marqués de Montealegre. Madrid, 29-XI-1754 (A.G.P., Libro de Registro 97. Cámara, Camería y Estampilla, Registro de órdenes de S.M. -1749-1759-).

Aceptado para su publicación en Abril de 1995

Dirección de las autoras. Departamento de Farmacia y Tecnología Farmacéutica (Historia de la Farmacia). Facultad de Farmacia. Universidad Complutense. 28040, Madrid. 